\title{
A STUDY ON THREE-DIMENSIONAL PRINTING REPLICATION FOR USABILITY OF ARTIFACTS
}

\author{
S. Hong, Y. H. Jo* \\ Dept of Cultural Heritage Conservation Science, Kongju National University - (h123kr@kongju.ac.kr, joyh@kongju.ac.kr)
}

KEY WORDS: Three-Dimensional Scanning and Printing, Replication, Design Mock-up, Modeling, Simulation

\begin{abstract}
:
In the field of cultural heritage, replication has been performed for preservation, exhibition, and education purposes. In particular, due to advancement in computer technology, replication which combines the three-dimensional (3D) scanning and printing has widely performed. These technologies have been able to ensure morphological similarity as well as to avoid damaging artifacts in a contactless manner. In this study, a design mock-up for producing replacements was made for the purpose of preserving original forms, usability, and mass production for ritual utensils used in ancestral memorial rites annually. 3D precision scanner was used to obtain external information of ritual utensils and shape information of pattern parts. The measurements on height, width, and thickness of the body, and two handles and three feet showed fine shape differences, respectively. Therefore, representative models were selected and reconstructed. In addition, the upper and lower parts of the body, handles, and feet were separately manufactured for mass production by using sand casting. A model manufactured during the reverse design like above was completed by considering average shrinkage (4\%) for the casting of copper-tin alloys. A model was completed and 3D-printed with a material extrusion technique, and a design mock-up for replication was created. In this study, a 3D printing technology was applied to ritual utensils and presented a replication methodology applicable to used artifacts. For this purpose, a model suitable for the replication method was produced based on the data obtained by 3D scanning of ritual utensils. A design mock-up, which is 3D-printed with a material extrusion technique, has enhanced design completeness by performing continuous design and dimensional inspection.
\end{abstract}

\section{INTRODUCTION}

Cultural heritages are often damaged by manmade and environmental factors, and damaged cultural artifact must be replicated for them to be used in record, preservation, research, and utilization. Replication of the artifacts is carried out using contact and contactless methods depending on the condition of the artifacts and the method of replication. Various materials such as gypsum, silicone, and synthetic resin have been widely used for contact replication, and replication using them mainly depends on conservator's intuition and techniques. Therefore, it is difficult to guarantee morphological similarity depending on the skill of the performer in such contact reproduction. In addition, directly contacting materials of artifacts may cause secondary damage (Jo et al., 2020).

To complement such contact replication methods, threedimensional (3D) digital technology has emerged as new replication technologies. Due to the recent advancement of computer technology, 3D scanning and printing technologies have been used as important methodologies in the replication processes. These digital technologies not only do not damage the artifacts, but also ensure morphological similarity. In this study, a design mock-up was manufactured for the purpose of preserving original forms, usability, and mass production for ritual utensils used in ancestral memorial rites annually. For this purpose, 3D precision scanning for digital recording was performed on a ritual utensil. In addition, modeling suitable for the replication method was carried out based on precise dimensional information, and the result was printed out with a $3 \mathrm{D}$ printer to manufacture a design mock-up.

\section{3D SCANNING AND SHAPE ANALYSIS}

The ritual utensil of this study consists of a cylindrical body, two handles, and three feet (Figure 1a). To obtain precise shape information for them, three-dimensional fixed high-precision precision scanning was performed (HDI Advance R3X, LMI Technologies). The obtained 58 individual scanned data was filtered, aligned, and merged to complete the final polygon mesh model (Figure 1b). The completed digital model consists of 7,132,407 points and 3,571,904 polygons. The distance between points shows a high resolution of $0.2 \mathrm{~mm}$, and the pattern of the handle as well as the manufacturing technique of
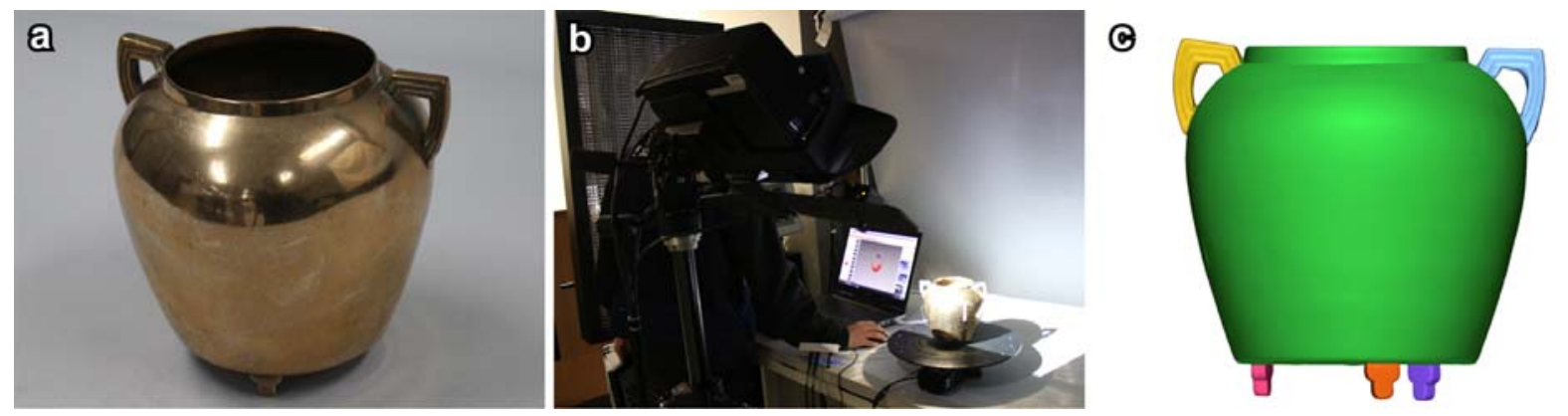

Figure 1. Occurrence and 3D scanning. (a) Original forms of ritual utensil. (b) Close-range 3D scan. (c) Polygon mesh model of ritual utensil. 
the ritual utensil is clearly visible (Figure 1c).

As a result of the actual measurement, the upper and lower widths of the body were approximately $140 \mathrm{~mm}$ and $114 \mathrm{~mm}$, respectively. Height was approximately $165 \mathrm{~mm}$. The crosssectional values of the body and the mouth rim part were found to be in the range of 0.89 to $3.85 \mathrm{~mm}$. The left and right handles showed a width of $33 \mathrm{~mm}$, a height of 45 to $46 \mathrm{~mm}$, and a thickness of $8 \mathrm{~mm}$. The left handle was $3 \mathrm{~mm}$, and the right handle was $8 \mathrm{~mm}$ apart from the mouth rim part. In addition, the three feet on the floor were measured to be 16.1 to $16.7 \mathrm{~mm}$ in width, 14.6 to $16.8 \mathrm{~mm}$ in height, and 7.2 to $7.4 \mathrm{~mm}$ in thickness. The distance from the floor center of the ritual utensil to each foot was in the range of 41 to $42 \mathrm{~mm}$. The two handles and the three feet showed slight differences in size and structure, respectively.

\section{DESIGN MOCK-UP MODELING}

Prior to modeling, the drawings suitable for sand casting were reconstructed by referring to the precise numerical data of the ritual utensil. Sand casting is a method of obtaining a product with a desired structure by pouring molten metal into a mold which is made of sand. Since this is a method of producing a mold by tamping sand and cutting it in half, the sand mold may collapse if the mold is bitten into a complicated or original structure. Therefore, this mold should be cast separately. Accordingly, the body, handle, and foot were modeled separately for manufacturing replicas of the ritual utensil (Geomagic Freeform Plus, 3D Systems).

For the reverse design of the body, thickness of the model was set by considering the maximum value of the thickness of the cross section and the work to be performed on the surface after casting. The upper and lower parts were manufactured by separating from the body in the purpose of allowing the casting to smoothly come out of the sand mold. Since two handles and three feet showed fine shape differences, a representative structure was selected according to experts' comment. As a result, drawings were reconstructed by selecting the right handle and B-shaped foot as a reference model and the modeling was accordingly carried out based on this reference model (Figure 2a). Then, rivets were protruded to connect the handle and foot to the body, and the body was drilled at the same position in the coupling part to complete the modeling (Figure 2b). The upper and lower body, handle, and foot models manufactured through the above modeling process considered the average shrinkage rate of copper-tin alloy castings of $4 \%$ and were enlarged by this figure to complete the final model.

\section{THREE-DIMENSIONAL PRINTING}

After the 3D modeling was completed, the model of the ritual utensil was printed out by $3 \mathrm{D}$ printing using the material extrusion method (Utimaker 3 extended, Ultimaker). The material used for 3D printing was PLA, and the upper and lower part of the body, handle, and foot were printed separately by setting the cumulation thickness of $0.15 \mathrm{~mm}$ and the nozzle temperature of $210^{\circ} \mathrm{C}$ (Figure 2c). In the case of the handle and foot, a support was created to prevent sagging under the influence of gravity. In particular, the handle was printed with a cumulation thickness of $0.10 \mathrm{~mm}$ because it is important to well express the fineness of the handle's pattern.

Through the printed output, it was possible to continuously verify the external design and dimensions of the replica model. In this step, the design was improved through the modeling correction and 3D printing re-printing process when an assembly error occurred. This process offered an effective methodology for the simulation and the review of body and structuring methods in hand and foot models. Conversely, postprocessing is performed to complete the model production when assembly is easy and there are no aesthetic errors.

\section{DISCUSSION AND CONCLUSION}

In general, replication has been mainly performed by contact and contactless methods for the purpose of exhibition, research, and conservation. However, few studies on replication of the relics are found. In addition, not only a contact method of replication, which is commonly practiced, may result in different results depending on the ability of the performer, but also simulation based on pre-inspection is impossible and result estimation is difficult. Moreover, the use of synthetic resin may cause secondary damage to the artifacts.

However, this study presents a methodology of replicating the relics, which is used by applying 3D scanning and printing technology, targeting the ritual utensil. To this end, dimensional information, which is difficult to measure by hand, was acquired by $3 \mathrm{D}$ scanning, and a model suitable for the replication method was manufactured based on such information. The design mock-up printed out by the material extrusion method was continuously used for external design review and dimensional verification, and the design completeness was enhanced through the modeling correction and reprinting processes when an assembly error occurred. In particular, modeling simulation and the printing process of the replication were important steps in reviewing the suitability of the design mock-up assembly and elevating the design completeness. a

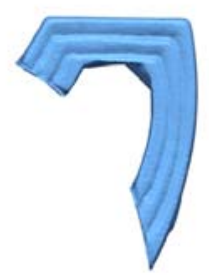

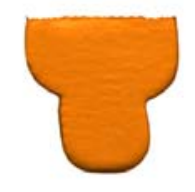
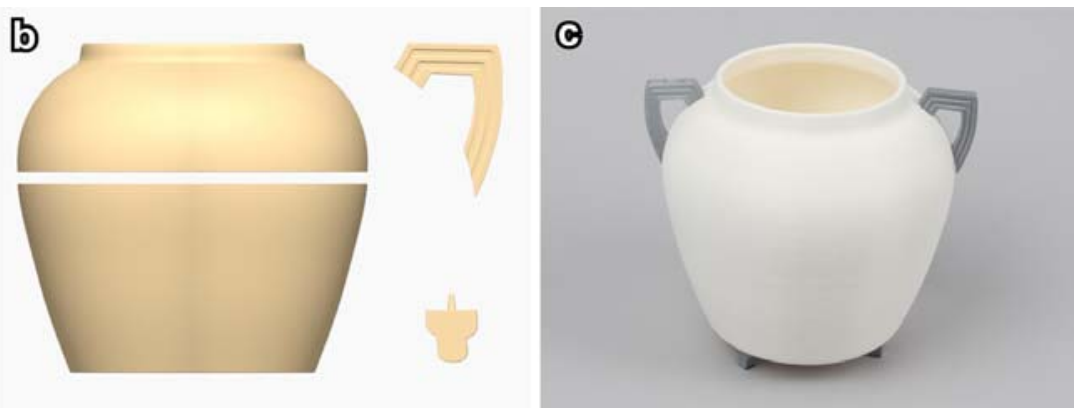

Figure 2. Design Mock-up modelling and results. (a) Reference models. (b) Replication models. (c) Design mock-up results. 
In this study, focused on establishing a method of replicating the relics using digital technology, and did not directly manufacture replicas using sand casting. In the future, it is necessary to study direct replica manufacturing through casting by grafting sand printing technology. In addition, it is estimated that 3D digital technology can be widely used for replicating similar cultural heritage if objective experiments on the shrinkage rate of alloy castings and classification of modeling methods suitable for various replication methods are accompanied.

\section{ACKNOWLEDGMENTS}

This work was supported by the National Research Foundation of Korea (NRF) grant funded by the Korean government (MSIT) (NRF 2019R1F1A060671). The authors would like to thank National Palace Museum of Korea for their support of this paper.

\section{REFERENCES}

Balletti, C., Ballarian, M., Guerra, F., 2017. 3D printing: state of the art and future perspectives. Journal of Cultural Heritage. 26, 172-182.

Dong, Q., Zhang, Q., Zhu, L., 2020, 3D scanning, modelling, and printing of Chinese classical garden rockeries: Zhanyuan's South Rockery. Heritage Science, 8, 61.

Jo, Y.H., Hong, S., Jo, S.Y., Kwon, Y.M., 2020. Noncontact restoration of missing parts of stone Buddha statue based on three-dimensional virtual modelling and assembly simulation. Heritage Science. 8(103), 1-12.
Jo, Y.H., Hong, S., 2019. Application of Three-dimensional Scanning, Haptic Modeling, and Printing Technologies for restoring Damaged Artifacts. Journal of Conservation Science. 35(1), 71-80.

Jo, Y.H., Lee, J.M., 2021. Three-Dimensional Digital-Mold Modeling and Sand-Printing for Replication Bronze Mirror. Journal of Conservation Science. 37(1), 25-33.

Segreto, T., Bottillo, A., Teti, R., Galantucci, L.M., Lavecchia, F., Galantucci, M.B., 2017. reverse engineering modeling for additive manufacturing of down scaled cultural artefacts. CIRP Encyclopedia of Production Engineering. 62, 481-486.

Vranich, A., 2018. Reconstructing ancient architecture at Tiwanaku, Bolivia: the potential and promise of 3D printing. Heritage Science. 6(65), 1-20.

Wilson, P.F., Stott, J., Warnet, J.M., Attridge, A., Smith, M.P., Williams, M.A., 2017. Evaluation of touchable 3D-printed replicas in museums. Curator: The Museum Journal. 60, 446465. 